\title{
Hygroscopic growth of urban aerosol particles in Beijing (China) during wintertime: a comparison of three experimental methods
}

\author{
J. Meier ${ }^{1}$, B. Wehner ${ }^{1}$, A. Massling ${ }^{1, *}$, W. Birmili ${ }^{1}$, A. Nowak $^{1}$, T. Gnauk ${ }^{1}$, E. Brüggemann ${ }^{1}$, H. Herrmann ${ }^{1}$, H. Min ${ }^{2}$, \\ and $\mathrm{A}$. Wiedensohler ${ }^{1}$ \\ ${ }^{1}$ Leibniz Institute for Tropospheric Research, Leipzig, Germany \\ ${ }^{2}$ College of Environmental Sciences, Peking University, Beijing, China \\ *now at: National Environmental Research Institute, Roskilde, Denmark
}

Received: 30 January 2009 - Published in Atmos. Chem. Phys. Discuss.: 16 March 2009

Revised: 3 September 2009 - Accepted: 7 September 2009 - Published: 21 September 2009

\begin{abstract}
The hygroscopic properties of atmospheric aerosols are highly relevant for the quantification of radiative effects in the atmosphere, but also of interest for the assessment of particle health effects upon inhalation. This article reports measurements of aerosol particle hygroscopicity in the highly polluted urban atmosphere of Beijing, China in January 2005. The meteorological conditions corresponded to a relatively cold and dry atmosphere. Three different methods were used: 1) A combination of Humidifying Differential Mobility Particle Sizer (H-DMPS) and Twin Differential Mobility Particle Sizer (TDMPS) measurements, 2) A Hygroscopic Tandem Differential Mobility Analyzer (H-TDMA), and 3) A simplistic solubility model fed by chemical particle composition determined from Micro Orifice Uniform Deposit Impactor (MOUDI) samples. From the H-DMPS and TDMPS particle number size distributions, a size-resolved descriptive hygroscopic growth factor (DHGF) was determined for the relative humidities (RH) 55\%, 77\% and $90 \%$, and particle diameters between 30 and $400 \mathrm{~nm}$. In Beijing, the highest DHGFs were observed for accumulation mode particles, $1.40( \pm 0.03)$ at $90 \%$ RH. DHGF decreased significantly with particle size, reaching $1.04( \pm 0.15)$ at $30 \mathrm{~nm}$. H-TDMA data also suggest a decrease in growth factor towards the biggest particles investigated $(350 \mathrm{~nm})$, associated with an increasing fraction of nearly hydrophobic particles. The agreement between the H-DMPS/TDMPS and H-TDMA methods was satisfactory in the accumulation mode size range $(100-400 \mathrm{~nm})$. In the Aitken mode range
\end{abstract}

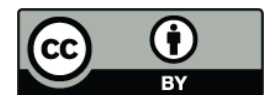

Correspondence to: J. Meier (jessica.meier@tropos.de)
$(<100 \mathrm{~nm})$, the H-DMPS/TDMPS method yielded growth factors lower by up to 0.1 at $90 \% \mathrm{RH}$. The application of the solubility model based on measured chemical composition clearly reproduced the size-dependent trend in hygroscopic particle growth observed by the other methods. In the case of aerosol dominated by inorganic ions, the compositionderived growth factors tended to agree $( \pm 0.05)$ or underestimate (up to 0.1) the values measured by the other two methods. In the case of aerosol dominated by organics, the reverse was true, with an overestimation of up to 0.2 . The results shed light on the experimental and methodological uncertainties that are still connected with the determination of hygroscopic growth factors.

\section{Introduction}

Beijing is one of the largest centres of industry and population in China, with about 15 million inhabitants only in its administrative district. The present city of Beijing has been shaped by the enormous economic growth that has occurred during the last two decades (Tang et al., 2005). This growth has come along with an enormous increase of energy consumption, derived mainly from fossil fuels like coal and natural gas. Although China has undertaken major efforts towards exploiting renewable energy sources, such as hydroelectric power, and cleaner combustion methods, fossil fuel combustion will remain the mainstay of the Chinese energy supply in the foreseeable future.

The combustion of fossil fuels has led to substantial environmental problems associated with the pollution gases and particles emitted into the atmosphere. In contrast to Europe

Published by Copernicus Publications on behalf of the European Geosciences Union. 
and the US, sulphur is still ubiquitous in fuel in China. Particle pollution has led to the prevalence of lung and heart diseases, with the total mortality suggested to increase by $11 \%$ with each doubling of the sulphur dioxide concentration (Xu et al., 1994). Indoor air quality is degraded by the use of unvented stoves fuelled by coal or biomass (Florig, 1997). The industrial rise in China has led to air pollution that has been acknowledged to greatly influence regional climate, and influences the worldwide level of air pollutants as well (Mage et al., 1996; Fenger, 1999).

Measurements of atmospheric particles in China have been intensified during the last decade, with the particular aim of better understanding the structure and composition of particulate matter, the related source and ageing processes, as well as its effect on climate and health. Bergin et al. (2001) observed that in Beijing, the single scattering albedo and the daily mean value for the $\mathrm{PM}_{2.5}$ mass concentration were considerably higher than, for instance, in the US industrial regions. Over the past 15 winters, the atmospheric optical depth over Beijing increased by a factor of about two, with the increasing local and regional energy production being a prime reason. In summer time, the optical depths may be even larger because of hygroscopic particle growth at high ambient relative humidity (RH) (Jinhuan and Liquan, 2000). In Beijing, natural aerosols have an impact on the local air quality as well: Poor visibility may be caused several times a year during dust storm events (Zhang et al., 2003; Sugimoto et al., 2003).

Long-term observations of particle number size distributions since 2002 have facilitated the identification of particular aerosol types and their relevance for the Beijing area: Coarse mineral particles from dust storms in inner Asia (Wehner et al., 2004), emissions of anthropogenic primary particles as well as secondary aerosol in the Aitken and accumulation modes (Wu et al., 2007), and ultrafine particles (diameter $<40 \mathrm{~nm}$ ) formed on a regional scale especially after the advent of relatively clean air masses from inner Asia (Wehner et al., 2008). Wehner et al. (2008) also confirmed the importance of slowly moving air masses under high pressure influence as a cause of the highest overall levels of particulate pollution in Beijing.

The hygroscopic growth of aerosol particles at ambient $\mathrm{RH}$ is instrumental in describing the ambient particle size distribution and its associated aerosol optical effects, such as visibility (Tang et al., 1981), the light scattering coefficient, and single scattering albedo (Charlson and Heintzenberg, 1995). Most atmospheric aerosols are externally mixed with respect to hygroscopicity, and consist of more and less hygroscopic sub-fractions (Swietlicki et al., 2008). The ratio between these fractions as well as their content of soluble material determines the hygroscopic growth of the overall aerosol. Particle hygroscopicity may vary as a function of time, place, and particle size (McMurry and Stolzenburg, 1989; Cocker et al., 2001; Swietlicki et al., 2008). The fraction of hydrophobic particles has been found to increase in the prox- imity of urban combustion sources (Ferron et al., 2005). In a one-year experiment in Leipzig, Germany, the urban sub$\mu \mathrm{m}$ aerosol was characterised as a mostly tri-modal mixture ("nearly hydrophobic", "less hygroscopic" and "more hygroscopic"), whose relative number depended on the time of day, day of the week, and season (Massling et al., 2005).

For China, only three experimental studies on the hygroscopic growth of tropospheric aerosol particles have been reported to the date of writing. Eichler et al. (2008) reported hygroscopic growth factors of the aerosol over the South Chinese Pearl River Delta, whose influence on the associated optical properties were quantified in Cheng et al. (2008). Measurements during the Carebeijing-2006 project served to characterise the hygroscopic properties of regional aerosols over the North China Plain (i.e. about $50 \mathrm{~km}$ south of Beijing) during summertime (Achtert et al., 2009). Massling et al. (2009) suggest that the hygroscopic growth factors of Aitken and accumulation mode particles in Beijing were slightly lower than comparable European observations, but nevertheless dominated by sulfate as main soluble component.

In January 2005, a specialised field campaign was conducted to characterise the hygroscopic growth of urban aerosols in Beijing in detail. As a novelty, three different experimental techniques were used to derive hygroscopic growth factors. These methods are either based on particle mobility spectrometers (H-DMPS/TDMPS, H-TDMA), or on the combination of chemical composition measurements with a solubility model. This paper discusses the experimental results as a function of the local weather situation, and provides a comparison between the different methods. Tables are provided to make the measurement data accessible for further calculations related to the effects of the ambient aerosol in Beijing

\section{Experimental}

\subsection{Measurement campaign Beijing}

Intensive field measurements were carried out in Beijing $\left(39.9^{\circ} \mathrm{N}, 116.4^{\circ} \mathrm{E}\right)$, China, between January 17 and 25 , 2005. All measurements were performed on the campus of Peking University located between the fourth and fifth circular road in the northern part of the city. The laboratory container for in-situ measurements was placed between a faculty building and a small street with very sparse vehicle traffic. The overall vehicle traffic on the campus is not very dense, and assumed to play a minor role for the measurements compared to sources in the city as a whole. Some contributions may, however, originate from domestic heating and cooking activities within the campus. Freight trucks are permitted to enter the city centre of Beijing only during nighttime. For this reason, Beijing is exposed to traffic particulate emissions around the clock: Passenger and light-duty traffic at daytime, 
and heavy duty and supply traffic at nighttime. Beijing's climate can be termed moderate continental: Hot and humid summers are followed by cold and dry winters. During our measurements low ambient temperatures $\left(-6.6-4.9^{\circ} \mathrm{C}\right.$, average: $\left.-1.1^{\circ} \mathrm{C}\right)$ and relative humidities $(14-71 \%$, average: $38 \%$ ) prevailed.

Our aerosol particle measurements included a Twin Differential Mobility Particle Sizer (TDMPS), a HumidifyingDifferential Mobility Particle Sizer (H-DMPS), a Hygroscopicity-Tandem Differential Mobility Analyzer (H-TDMA), and chemical particle analysis of samples collected using a Micro Orifice Uniform Deposit Impactor (MOUDI). The TDMPS and H-DMPS instruments were placed inside an air-conditioned measurement container. Both systems were supplied with aerosol that had passed through a $\mathrm{PM}_{10}$ impaction inlet mounted $2.3 \mathrm{~m}$ above the container roof. The MOUDI and the H-TDMA were placed inside an air-conditioned laboratory on the top (20 m height) of a nearby building, distant at $200 \mathrm{~m}$.

\subsection{Twin Differential Mobility Particle Sizer}

A Twin Differential Mobility Particle Sizer (TDMPS) was used to measure dry number size distributions of ambient particles (3-900 nm). Atmospheric particles were dried to a relative humidity (RH) below $20 \%$ in a diffusion dryer upstream of the instrument. Sheath air was supplied at a relative humidity below 5\% for the Differential Mobility Analyzers (DMAs). The TDMPS consists of two DMA subsystems covering size ranges of 3-22 nm and 22-900 nm, respectively (Birmili et al., 1999). The data processing scheme includes a multiple charge inversion that accounts for the DMA transfer functions, and the counting efficiencies of the condensation particle counters. As a last step, the losses of particles due to diffusion in the inlet system were corrected by using an analytical formula for laminar flow.

\subsection{The Humidifying DMPS}

The Humidifying DMPS (H-DMPS) is a recently built-up variant of the DMPS that measures particle number size distributions at controlled relative humidity (Eichler et al., 2008; Birmili et al., 2009). Briefly, the H-DMPS consists of a single DMA measuring particles across the diameter range $22-900 \mathrm{~nm}$. Particles are first humidified to above $90 \% \mathrm{RH}$ upstream of the DMA, and subsequently dried down to target RH. The chosen RH ensures the exceedance of the deliquescence points of most common inorganic salts with atmospheric relevance. The sample aerosol is conditioned to the target RH of either $55 \%, 77 \%$ or $90 \%$ before entering the bipolar charger and the DMA. Sheath air is supplied to the DMA at the same RH. Small fluctuations in room temperature may lead to erroneous RHs during particle classification. Therefore, a careful quality control of the H-DMPS size distributions were needed with RH in the DMA excess flow be- ing used as the main quality control parameter. A detailed account on the quality control of the H-DMPS data is given in Birmili et al. (2009).

\subsection{The Hygroscopic Tandem DMA}

The H-TDMA instrument used in this study is based on the set-up originally described by Rader and McMurry (1986). It consists of two DMAs and an aerosol humidifier, which is positioned between the DMAs. The first DMA selects a monodisperse fraction of particles at dry conditions. These particles with defined particle sizes (here $D_{p}=30,50,80$, 150,250 and $350 \mathrm{~nm}$ ) pass through a humidifier to be conditioned to defined RH (here: 90\%). The second DMA was operated with a sheath air of $\mathrm{RH}=90 \%$ and coupled to a condensation particle counter to measure the number size distribution of the humidified altered aerosol. The measured number size distribution provides a hygroscopic growth factor spectrum depending on the state of mixing. More details of the instrument can be found in Massling et al. (2005).

\subsection{Chemical particle sampling and analysis}

Bulk particles were collected across an ambient aerodynamic diameter range $0.056-18 \mu \mathrm{m}$ by a Micro Orifice Uniform Deposit Impactor (MOUDI; Marple et al., 1991). After transport to the laboratory, the samples were analysed for carbonaceous components as well as inorganic ions. Before and after exposure the impactor foils were equilibrated for $48 \mathrm{~h}$ at constant temperature $\left(20 \pm 2^{\circ} \mathrm{C}\right)$ and relative humidity $(50 \pm 5 \%)$. The foils were weighed by a microbalance UMT-2 (Mettler-Toledo, Giessen, Germany) with a reading precision of $0.1 \mu \mathrm{g}$ and a standard deviation of $\leq 1 \mu \mathrm{g}$. The absolute particle mass on the foils varied from $5 \mu \mathrm{g}$ $\left(0.056<D_{\text {aero }}<0.1 \mu \mathrm{m}\right)$ to $3500 \mu \mathrm{g}\left(0.32<D_{\text {aero }}<0.56 \mu \mathrm{m}\right)$ corresponding to instrumental uncertainties of 20 and $0.03 \%$.

Cations were determined by ion chromatography (ICMetrohm AG, Herisau, Switzerland), anions by capillary zone electrophoresis (CE-Spectra Phoresis 1000, Thermo Separation Products, USA). A detailed description is given by Brüggemann and Rolle (1998) and Neusüss et al. (2000). Particulate carbon determination was performed with a thermographic method similar to the VDI-guideline (VDI 2465, Part 2) in Germany using a carbon analyser C-mat 5500 (Ströhlein, Viersen, Germany). The aluminium foil aliquot was in a first step heated to $650^{\circ} \mathrm{C}$ under nitrogen atmosphere for eight minutes. Those carbon compounds that evaporate under these conditions are referred to as organic carbon (OC). Evaporated $\mathrm{OC}$ is oxidised quantitatively on a $\mathrm{CuO}$ catalyst at $850^{\circ} \mathrm{C}$ to $\mathrm{CO}_{2}$ and measured in a NDIR detector. In a second step, the remaining elemental carbon (EC) was determined by burning the sample under oxygen atmosphere at $650^{\circ} \mathrm{C}$ for eight minutes, whereby all carbon is oxidised to $\mathrm{CO}_{2}$ and then detected also by IR absorption. Further details of the carbon analysis are described in Neusüss et al. (2000). 


\section{Calculation of hygroscopic growth factors}

The hygroscopic growth factor $G F$ of a particle is defined as the quotient between a particle's diameter at a given relative humidity $\mathrm{RH}_{1}$, and its diameter at a (typically lower) reference humidity $\mathrm{RH}_{0}$.

$G F=\frac{D_{p}\left(\mathrm{RH}_{1}\right)}{D_{p}\left(\mathrm{RH}_{0}\right)}$

Three methods to derive hygroscopic growth factors are described in the following.

\subsection{Descriptive Hygroscopic Growth Factors from TDMPS and H-DMPS}

The H-DMPS and TDMPS measurements were synchronised and available at $10 \mathrm{~min}$ time resolution. Descriptive hygroscopic growth factors were calculated from these corresponding dry and humidified distributions using the summation method (SM; Birmili et al., 2009). The SM derives growth factors averaging over all hygroscopic particle fractions, so that its output function was termed "Descriptive Hygroscopic Growth Factor" (DHGF). The DHGF represents an average hygroscopic growth factor for a dry monodisperse population rather than the individual growth factors of the less and more hygroscopic particle fractions.

Segments of equal particle number under the dry and humidified (here: $55 \%, 77 \%$ and $90 \% \mathrm{RH}$ ) number size distributions are allocated, starting at the upper tail of the number size distribution, and subsequently moving downwards. It is assumed that the particles in the "dry" number segment grow, on average, to the corresponding "wet" number segment. The DHGF is the diameter ratio of the mean diameters of both segments. For further details of the calculation see Birmili et al. (2009).

We are aware that the assumption of homogeneously mixed particles is not true for the atmosphere. There, the particle population at one dry diameter is usually an external mixture (Swietlicki et al., 2008). However, the SM is assumed to yield reasonable results as long as no drastic (i.e. step-wise) changes occur in terms of this mixture with particle diameter. The upper size limit of the SM is limited by the counting statistics in the upper accumulation mode range, whereas its lower size limit is defined by the degree of absolute comparability between TDMPS and H-DMPS size distributions. Taking both issues into account, the acceptable range of DHGFs is $30-500 \mathrm{~nm}$. The uncertainty of the final DHGFs were determined by a sensitivity study (Birmili et al., 2009). A typical uncertainty of 0.05 in growth factor was found for particles bigger than $70 \mathrm{~nm}$. The uncertainty increases towards lower particle sizes, reaching about 0.1 at $30 \mathrm{~nm}$.

\subsection{Growth factors from H-TDMA}

Using the H-TDMA data, the sub- $\mu \mathrm{m}$ particles were separated into three classes named "nearly hydrophobic", "less hygroscopic" and "more hygroscopic" (Massling et al., 2003). Three individual growth factors $\left(G F_{1}, G F_{2}, G F_{3}\right)$ and corresponding number fractions $\left(n f_{1}, n f_{2}, n f_{3}\right)$ were obtained for each dry diameter under study. To make the results comparable with the DHGF from the H-DMPS/TDMPS measurements, and those derived from chemical particle composition, a mean $\overline{\mathrm{GF}}$ was calculated by

$\overline{\mathrm{GF}}=\sqrt[3]{n f_{1} \cdot G F_{1}^{3}+n f_{2} \cdot G F_{2}^{3}+n f_{3} \cdot G F_{3}^{3}}$

The uncertainty of the particular growth factors is known to be 5\% (Massling et al., 2009). For this study, the uncertainty of the particular number fractions was estimated to be as small as $<3 \%$. The error of $\overline{\mathrm{GF}}$ was calculated by using the Gaussian error propagation.

\subsection{Growth factors based on chemical composition}

Chemical composition-based hygroscopic growth factors (CHGFs) were obtained using the relative dry mass fractions of different compounds in a solubility model. Chemical particle composition of MOUDI samples yielded the concentrations of soluble ions such as $\mathrm{Na}^{+}, \mathrm{NH}_{4}^{+}, \mathrm{K}^{+}, \mathrm{Ca}^{2+}, \mathrm{Mg}^{2+}$, $\mathrm{Cl}^{-}, \mathrm{SO}_{4}^{2-}$ and $\mathrm{NO}_{3}^{-}$, elemental carbon (EC) and organic carbon (OC). Organic carbon (OC) was converted to organic matter (OM) by multiplication with 1.6 to account for the non-carbon elements (Turpin and Lim, 2001).

Anions and cations were associated to form specific ion combinations corresponding to inorganic salts. $\left(\mathrm{NH}_{4}\right)_{2} \mathrm{SO}_{4}$, $\mathrm{NH}_{4} \mathrm{NO}_{3}, \mathrm{NaNO}_{3}$, and $\mathrm{NaCl}$ were assumed to constitute the major inorganic compounds in our samples although the latter played only a marginal role since due to the absence of maritime air masses during our observations. $\mathrm{NaNO}_{3}$ was considered an educt of chemical processes converting $\mathrm{NaCl}$ during transport over land. This above assumptions are supported by the high correlation between $\mathrm{NH}_{4}^{+}$ and $\left[2 * \mathrm{SO}_{4}^{-2}+\mathrm{NO}_{3}^{-}\right]$across all impactor stages analysed (I1: $\mathrm{R}=0.97 ; \mathrm{I} 2: \mathrm{R}=0.98 ; \mathrm{I} 3: \mathrm{R}=0.97$ ). Sulphuric acid $\left(\mathrm{H}_{2} \mathrm{SO}_{4}\right)$ was considered an additional species of sulphate ions as long as these were not fully neutralised by cations. It is of significance in which order the ion combinations are accomplished. Six main options were pursued, listed in Table 1 . In each run of the model described in the table, ions are first apportioned to the species labelled "1st apportionment". The remaining ions are apportioned to the species labelled "2nd apportionment" and so on.

Using their molar masses, the mass fractions of each compound and the material density was calculated for each impactor stage. As the impactor samples were weighed under standard conditions of $52 \% \mathrm{RH}$, the specific amount of water attracted at this humidity needed to be subtracted. To obtain 
the dry mass of a sample, the water uptake based on the theoretical hygroscopic growth of the model salts at $52 \% \mathrm{RH}$ (Tang and Munkelwitz, 1994) was subtracted from the (humid) particle mass.

An average particle density of $1.7 \mathrm{~g} \mathrm{~cm}^{-3}$ was chosen to calculate the dry particle volume for each impactor sample. The particular value of 1.7 was motivated as follows: First, the aerodynamic particle size distributions from an aerodynamic particle sizer and the mobility size distributions from the TDMPS were reconciled for the instruments' overlap size range $610-800 \mathrm{~nm}$, based on a biennial statistics, by this apparent density (Wu et al., 2008). Second, $1.7 \mathrm{~g} \mathrm{~cm}^{-3}$ was also the effective density of particles in $\mathrm{PM}_{2.5}$ derived over a two-year period for a European city (Pitz et al., 2008). The material densities of ammonium sulphate and nitrate are 1.77 and $1.73 \mathrm{~g} \mathrm{~cm}^{-3}$, respectively. Contributions of $\mathrm{OM}$ tend to decrease the material density while those of crustal material lead to an increase. Fresh atmospheric EC has been identified to have an effective density around $1 \mathrm{~g} \mathrm{~cm}^{-3}$ but could reach $2 \mathrm{~g} \mathrm{~cm}^{-3}$ if the carbon agglomerates were present in compacted form. Yue et al. (2009) report effective densities of 1.68 and $1.43 \mathrm{~g} \mathrm{~cm}^{-3}$ for $\mathrm{PM}_{10}$ and $\mathrm{PM}_{1}$ in Beijing, however, for summer time only. In summary, a high degree of uncertainty remains attached to the estimate of particle density. A sensitivity analysis showed that the resulting hygroscopic growth factor would decrease by 0.03 when choosing 1.5 instead of $1.7 \mathrm{~g} \mathrm{~cm}^{-3}$ as a particle density.

Another important assumption refers to the growth behaviour of EC and OM. In our approach, both are treated as insoluble $(G F=1)$. For atmospheric soot, the non-existing growth, at least for RH up to $90 \%$, was shown in H-TDMA measurements (Weingartner et al., 1997; Massling et al., 2005). Field measurements of continental organic aerosols suggested relatively low growth factors $(1.08-1.17$ at $90 \%$ $\mathrm{RH})$, but also emphasised the considerable uncertainty related to the growth behaviour of the organic fraction of the aerosol (Gysel et al., 2004). A sensitivity analysis of our solubility model suggested that the total hygroscopic growth factor would increase by 0.1 when selecting a growth factor of 1.2 (at $90 \% \mathrm{RH}$ ) instead of 1.0 for OM. This value of 0.1 illustrates the range of uncertainty associated with the incomplete knowledge on the hygroscopic growth of the organic particle fraction.

The chemical composition-based hygroscopic growth factor (CHGF) in a particular sample was calculated using the Zdanovskii-Stokes-Robinson-Relation (ZSR) (Zdanovskii, 1948; Stokes and Robinson, 1966). The hygroscopic growth of each of the compounds listed in Table 1 follows the empirical parameterisations of (Tang and Munkelwitz, 1994) based on laboratory measurements.

\section{Results}

\subsection{Meteorological overview}

During the measurement campaign between January 17 and 25, 2005, the meteorological situation in northern China underwent several changes, associated with alterations in the observed particle mass concentrations and chemical composition. Figure 1 presents the particle mass size distribution and the total particle mass $\left(\mathrm{PM}_{1}: D_{\text {aero }} \leq 1 \mu \mathrm{m}\right)$ calculated by means of the particle number size distribution of dry particles (measured with TDMPS), and assuming a mean particle density of $1.7 \mathrm{~g} \mathrm{~cm}^{-3}$. Based on the meteorological conditions, indicated by temperature, relative humidity, wind speed, and wind direction, the entire measurement period was classified into three distinct periods associated with different air masses. These are named A1, A2 and A 3 in the following.

\subsubsection{Air Mass A1 (moderate polluted)}

Between 17 January 12:00 and 20 January 19:00, relatively clean air masses were advected to Beijing from northwestern regions, i.e. the less populated and industrialised part of China (Fig. 2, red). Our observation is in line with the statistics-based observations of Wehner et al. (2008). Since Beijing is a constant emitter of particles and precursor gases during day and nighttime, the accumulation of primary and secondary particle number and mass at a particular time depends additionally on local features, such as the transport time of the air over the city, and atmospheric stratification. During daytime, the wind speed was higher than during nighttime (maximum day: $7.7 \mathrm{~m} \mathrm{~s}^{-1}$; maximum night: $5.5 \mathrm{~m} \mathrm{~s}^{-1}$ ). Due to calm winds, the accumulation of pollution aerosol was the greatest during nighttime. Mainly clean continental aerosol was observed during daytime and at the beginning of the period. The maximum particle mass concentration was determined to $176 \mu_{\mathrm{g} \mathrm{m}}^{-3}$ (Fig. 1). Air mass A1 was characterised as dry, with an average relative humidity of $28 \%$.

\subsubsection{Air Mass A2 (high polluted)}

The second time period (20 January, 19:00-24 January, 01:00) features the advection of air from southerly directions (Fig. 2, green), where the density of population and industries is significant. The accumulation of aerosol number and mass was enhanced due to the low wind speed (average: $1 \mathrm{~m} \mathrm{~s}^{-1}$ ), as it was also described by Wehner et al. (2008) (trajectory clusters 5 and 6). The aerosol in air mass A2 can therefore be described as urban pollution on top of an existing high regional background. During the entire period, the particle mass concentrations increased from day to day, with individual maxima at night in the beginning of the period (Fig. 1). At the end of the period, the particle mass concentration reached a maximum of $520 \mu \mathrm{g} \mathrm{m}^{-3}$. The relative 
Table 1. Scheme of apportioning inorganic ion towards paired compounds.

\begin{tabular}{lcccc}
\hline & 1st apportionment & 2nd apportionment & 3rd apportionment & 4th apportionment \\
\hline Run 1 & $\mathrm{NH}_{4} \mathrm{NO}_{3}$ & $\left(\mathrm{NH}_{4}\right)_{2} \mathrm{SO}_{4}$ & $\mathrm{H}_{2} \mathrm{SO}_{4}$ & \\
Run 2 & $\left(\mathrm{NH}_{4}\right)_{2} \mathrm{SO}_{4}$ & $\mathrm{NH}_{4} \mathrm{NO}_{3}$ & $\mathrm{NaCl}$ & \\
Run 3 & $\left(\mathrm{NH}_{4}\right)_{2} \mathrm{SO}_{4}$ & $\mathrm{NH}_{4} \mathrm{NO}_{3}$ & $\mathrm{NaNO}_{3}$ & \\
Run 4 & $\mathrm{NH}_{4} \mathrm{NO}_{3}$ & $\left(\mathrm{NH}_{4}\right)_{2} \mathrm{SO}_{4}$ & $\mathrm{NaNO}_{3}$ & \\
Run 5 & $\left(\mathrm{NH}_{4}\right)_{2} \mathrm{SO}_{4}$ & $\mathrm{NH}_{4} \mathrm{NO}_{3}$ & $\mathrm{H}_{2} \mathrm{SO}_{4}$ & $\mathrm{NaCl}$ \\
Run 6 & $\mathrm{NH}_{4} \mathrm{NO}_{3}$ & $\left(\mathrm{NH}_{4}\right)_{2} \mathrm{SO}_{4}$ & $\mathrm{H}_{2} \mathrm{SO}_{4}$ & $\mathrm{NaCl}$ \\
\hline
\end{tabular}

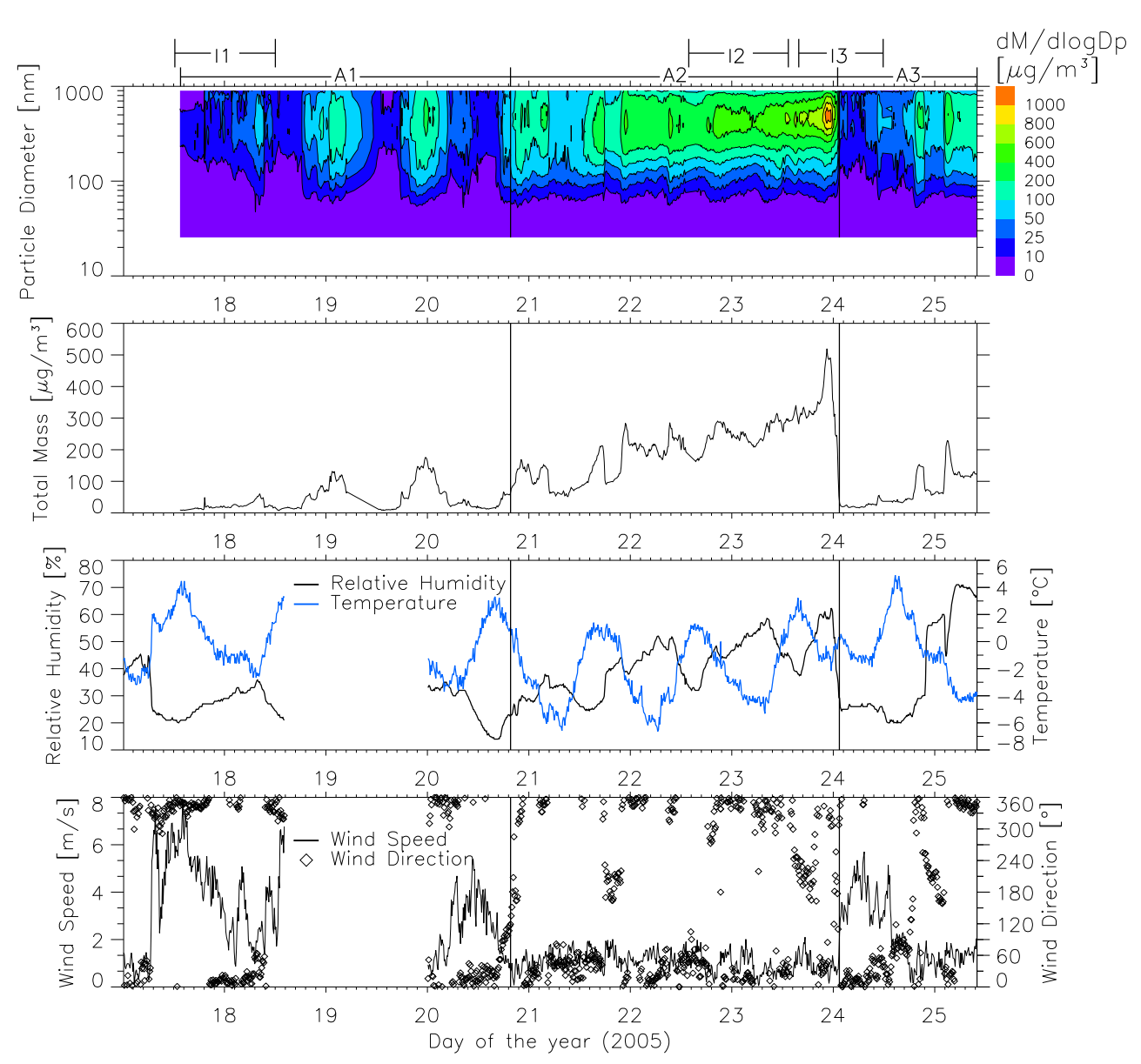

Fig. 1. Particle mass size distribution, temperature, relative humidity, wind speed and wind direction during the measurement campaign in Beijing from 17 to 25 January 2005.

humidity increased during the whole time period with a maximum of $62 \%$ shortly before the air mass change.

\subsubsection{Air Mass A3 (less polluted)}

A sudden change in meteorological conditions led to an abrupt decrease in particle mass concentration, starting on 24 January, 01:00, and lasting until 25 January, 10:00 (Fig. 1). The relatively clean air mass (Fig. 2, blue) reached Beijing from northerly directions, passing over mountainous terrain.
Due to Foehn effects, the relative humidity decreased rapidly from $62 \%$ to $24 \%$. In the beginning of the period, the wind speed increased from $1 \mathrm{~m} \mathrm{~s}^{-1}$ to nearly $6 \mathrm{~m} \mathrm{~s}^{-1}$ leading to lower particle mass concentrations (maximum: $229 \mu \mathrm{g} \mathrm{m}^{-3}$ ) in clean continental air. Later, the wind calmed down to around $2 \mathrm{~m} \mathrm{~s}^{-1}$ causing accumulation of the particle mass concentration of mainly urban origin. 


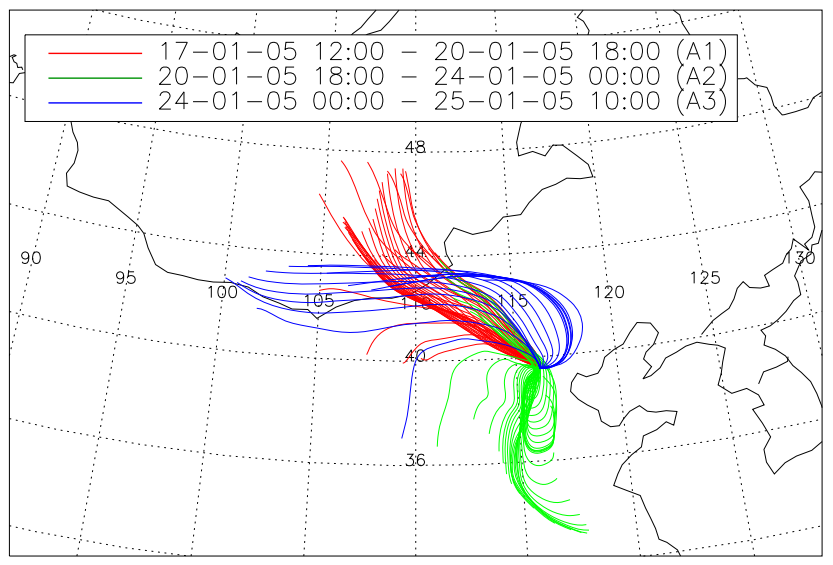

Fig. 2. Back trajectories in Beijing (air mass A1, red), 20 January 2005 19:00 and 24 January 2005 01:00 (air mass A2, green), 24 January 2005 01:00 and 25 January 2005 10:00 (air mass A3, blue). Trajectory length was $48 \mathrm{~h}$. Trajectories were started every three hour. Source: HYSPLIT website (Draxler and Hess, 2004).

\subsection{Impactor sampling}

Three MOUDI samples of atmospheric particles for chemical analysis were taken during the entire field study one each during air mass period 1 and 2 , and one in the overlap period between air mass 2 and air mass 3 . The samples were taken from midday of January 17 to midday of 18 January (I1), from January 22, 14:00, to 23 January, 14:00 (I2) and from 23 January, 16:00 to midday of 24 January (I3). The first two impactor sampling periods (I1 and I2) are representative for the conditions found during air mass A1 and A2, respectively. Impactor sampling period I3, however, is a mixture of the conditions during $\mathrm{A} 2$ and $\mathrm{A} 3$.

Figure 3 displays the chemical mass fractions for the three impactor sampling periods I1, I2, and I3, and nine aerodynamic diameters ranges, respectively. Unspecified material was most predominant in coarse particles $\left(D_{\text {aero }} \geq 1.8 \mu \mathrm{m}\right)$. In our analysis, unspecified material is mainly associated with insoluble minerals, such as silicates and iron oxides, but also remnants of water. Fine particles $\left(D_{\text {aero }} \leq 1 \mu \mathrm{m}\right)$ contained an increasing fraction of inorganic ions as well as OM and EC with decreasing particle size. Figure 4 shows back trajectories for the three measurement periods. Table 2 provides the corresponding average numbers. The differences between the sampling periods I1, I2 and I 3 reflect the largescale origin of these atmospheric aerosols. In addition the ratio between $\mathrm{OM}$ and $\mathrm{EC}$ and soluble and insoluble material, respectively, for three diameter ranges is listed.

\subsubsection{Impactor sampling period I1 (relatively clean)}

The first sampling period (17 January, 12:00-18 January $2005,12: 00)$ was characterised by low total mass concen-
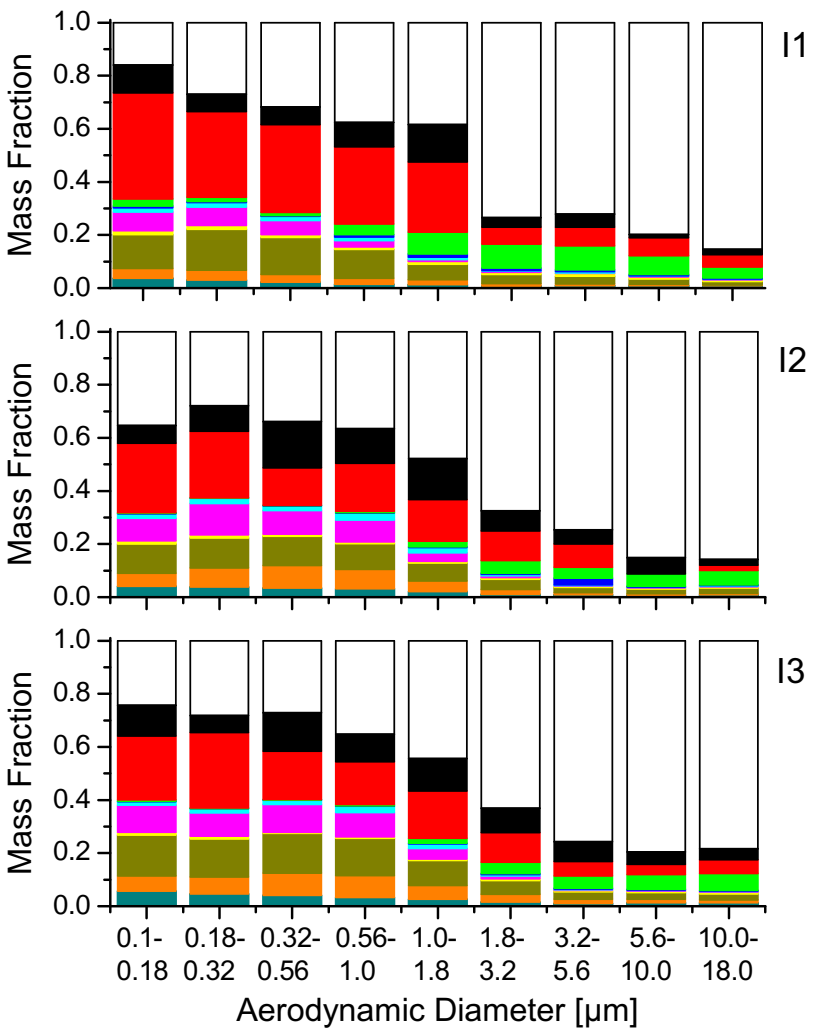

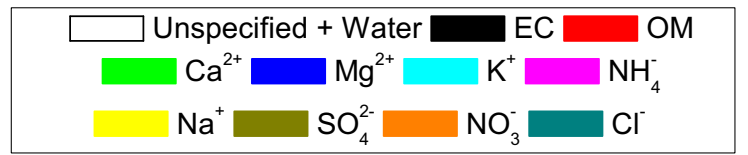

Fig. 3. Mass fractions of inorganic ions, EC, OM and the unspecified remainder within nine aerodynamic size classes during the three measurement periods 17 January 2005 to 18 January 2005 (I1, top), 22 January 2005 to 23 January 2005 (I2, middle) and 23 January 2005 to 24 January 2005 (I3, bottom). The unspecified material is assumed to consist of insoluble material.

trations $\left(27 \mu \mathrm{g} \mathrm{m}^{-3}\right.$ for $0.1-18 \mu \mathrm{m}$ particles). During this period I1, the air mass was transported from western and northwestern regions to Beijing (Fig. 4, red). The ratio of OM to EC was larger than 2 for all three particle size ranges (Table 2). The high OM/EC ratios are suggestive of a continentally aged aerosol, due to the generation of OM from gasto-particle conversion (Cao et al., 2003). The influence of freshly emitted aerosol was estimated low for this sampling period. Being a sub-period of air mass A1, the period I1 was characterised as "clean continental".

\subsubsection{Impactor sampling period I2 (polluted)}

The second sampling period (22 January, 14:00-23 January $2005,14: 00)$, in contrast, was characterised by high total mass concentrations $\left(275 \mu \mathrm{g} \mathrm{m}^{-3}\left(D_{\text {aero }}=0.1-18 \mu \mathrm{m}\right)\right)$. As 
Table 2. Total mass and analysed mass of inorganic ions, EC, OM and the unspecified material. Additionally the ratio of OM/EC and soluble/insoluble material for the three impactor sampling periods (I1, I2, I3) with the MOUDI.

\begin{tabular}{ccccccccc}
\hline Time Period & $\begin{array}{c}\text { Aerodynamic } \\
\text { Diameter } \\
{[\mu \mathrm{m}]}\end{array}$ & $\begin{array}{c}\text { Total Mass } \\
{\left[\mu \mathrm{g} \mathrm{m}^{-3}\right]}\end{array}$ & $\begin{array}{c}\text { Inorganic Ions } \\
{\left[\mu \mathrm{g} \mathrm{m}^{-3}\right]}\end{array}$ & $\begin{array}{c}\mathrm{OM} \\
{\left[\mu \mathrm{g} \mathrm{m}^{-3}\right]}\end{array}$ & $\begin{array}{c}\mathrm{EC} \\
{\left[\mu \mathrm{g} \mathrm{m}^{-3}\right]}\end{array}$ & $\begin{array}{c}\text { Unspecified } \\
{\left[\mu \mathrm{g} \mathrm{m}^{-3}\right]}\end{array}$ & & \\
\hline $\mathrm{I} 1$ & $0.056-0.1$ & 0.83 & 0.28 & 0.33 & 0.09 & 0.13 & 3.83 & 0.51 \\
$(17-01-200512: 00$ & $0.18-0.32$ & 8.47 & 2.54 & 2.78 & 0.57 & 1.54 & 4.91 & 0.52 \\
$-18-01-200512: 00)$ & $0.56-10$ & 17.9 & 2.59 & 1.96 & 0.8 & 11.8 & 2.45 & 1.23 \\
\hline I2 & $0.056-0.1$ & 7.71 & 2.46 & 2.01 & 0.51 & 2.73 & 3.92 & 0.47 \\
$(22-01-200514: 00$ & $0.18-0.32$ & 116 & 41.0 & 19.0 & 18.4 & 38.2 & 1.03 & 0.54 \\
$-23-01-200514: 00)$ & $0.56-10$ & 150 & 24.5 & 13.6 & 12.2 & 100 & 1.12 & 0.19 \\
\hline I3 & $0.056-0.1$ & 3.58 & 1.44 & 0.86 & 0.42 & 0.87 & 2.06 & 0.67 \\
$-24-01-200516: 00$ & $0.18-0.32$ & 56.8 & 22.5 & 11.4 & 7.34 & 15.5 & 1.56 & 0.66 \\
$-24-200512: 00)$ & $0.56-10$ & 161 & 31.4 & 15.5 & 12.8 & 102 & 1.21 & 0.24 \\
\hline
\end{tabular}

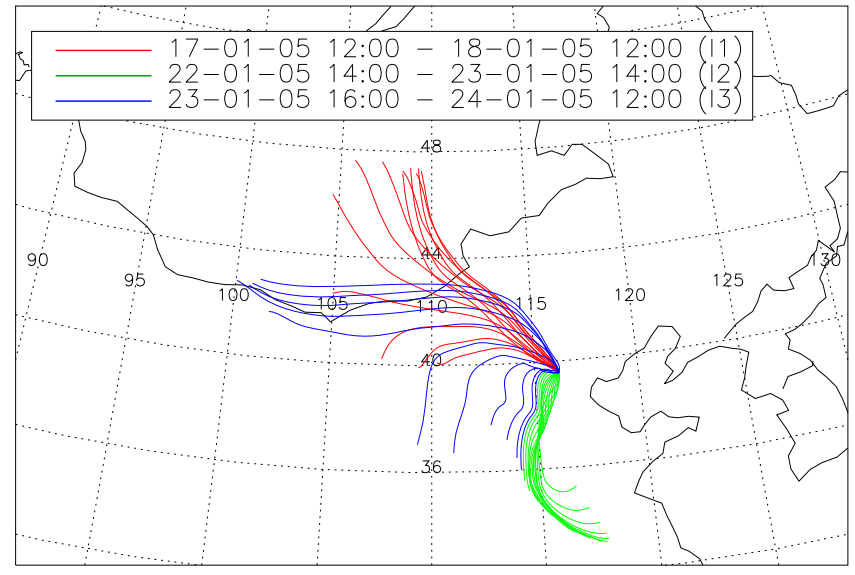

Fig. 4. Back trajectories arriving at Beijing during the impactor sampling periods I1 (red), I2 (green) and I3 (blue). Trajectory length is $48 \mathrm{~h}$. Each trajectory represents a three hour interval. Source: HYSPLIT website (Draxler and Hess, 2004).

described in Sect. 4.1.2 and Fig. 4, the air mass arrived slowly from southerly directions and contained a significant amount of regional pollution aerosol. Due to the low wind speeds and poor dispersion conditions, local pollution added on top of this background. The OM/EC ratio of approximately one for $D_{\text {aero }} \geq 0.18 \mu \mathrm{m}$ supports this interpretation. Low OM/EC ratios have been associated with direct vehicular emissions (Viidanoja et al., 2002).

\subsubsection{Impactor sampling period I3 (mixed)}

Unfortunately, the last sampling period (23 January, 16:0024 January 2005, 12:00) covered the two rather different air mass A2 and A3. As illustrated in Fig. 1, air mass A2 dominated the aerosol mass concentration collected during period
I3. According to the TDMPS measurements, $90 \%$ of the particle mass in $\mathrm{I} 3$ was collected during the last hours of period A2 (total mass concentration: $222 \mu \mathrm{g} \mathrm{m}^{-3}$ for $0.1-18 \mu \mathrm{m}$ particles). Not surprisingly, the OM/EC ratios during I3 differ only slightly from $\mathrm{I} 2$, indicating again an addition of regional and urban influence.

\subsection{Hygroscopic particle growth factors}

\subsubsection{Descriptive hygroscopic growth factors}

The descriptive hygroscopic growth factors (DHGFs) calculated from the TDMPS and H-DMPS measurements are illustrated in Fig. 5 and summarised in Table 3. The DHGFs were time-averaged for each air mass and relative humidity $(\mathrm{RH}=55 \%, 77 \%$ and $90 \%)$. In the accumulation mode range $(>120 \mathrm{~nm})$ the DHGFs ranged between 1.33 and 1.4 at $90 \% \mathrm{RH}$. This is slightly higher than DHGFs determined for a clean continental background atmosphere in Northern Europe (1.25-1.45; Birmili et al., 2009), but lower than corresponding data from the South Chinese Pearl River Delta in autumn 2004 (1.5; Eichler et al., 2008). The DHGFs decrease with particle size, and reach values between 1.04 and 1.09 at the lowest size channel $30 \mathrm{~nm}$.

Air mass A1 reached Beijing from northwesterly directions with relatively high wind speeds during daytime and low wind speeds during nighttime. Unfortunately, H-DMPS measurements were available only for the nighttime, where the impact of pollution aerosol was most noticeable. Our observations during air mass A1 featured the lowest DHGFs of all three periods (Fig. 5). At all three relative humidities the DHGF curves show a pronounced maximum around $D_{p}=110 \mathrm{~nm}$. Our conclusion is that here, the aerosol is most hygroscopic around 100-120 nm, and less hygroscopic for bigger and smaller particle sizes. As shown below, these low DHGFs were associated with high number fractions of nearly hydrophobic particles. 

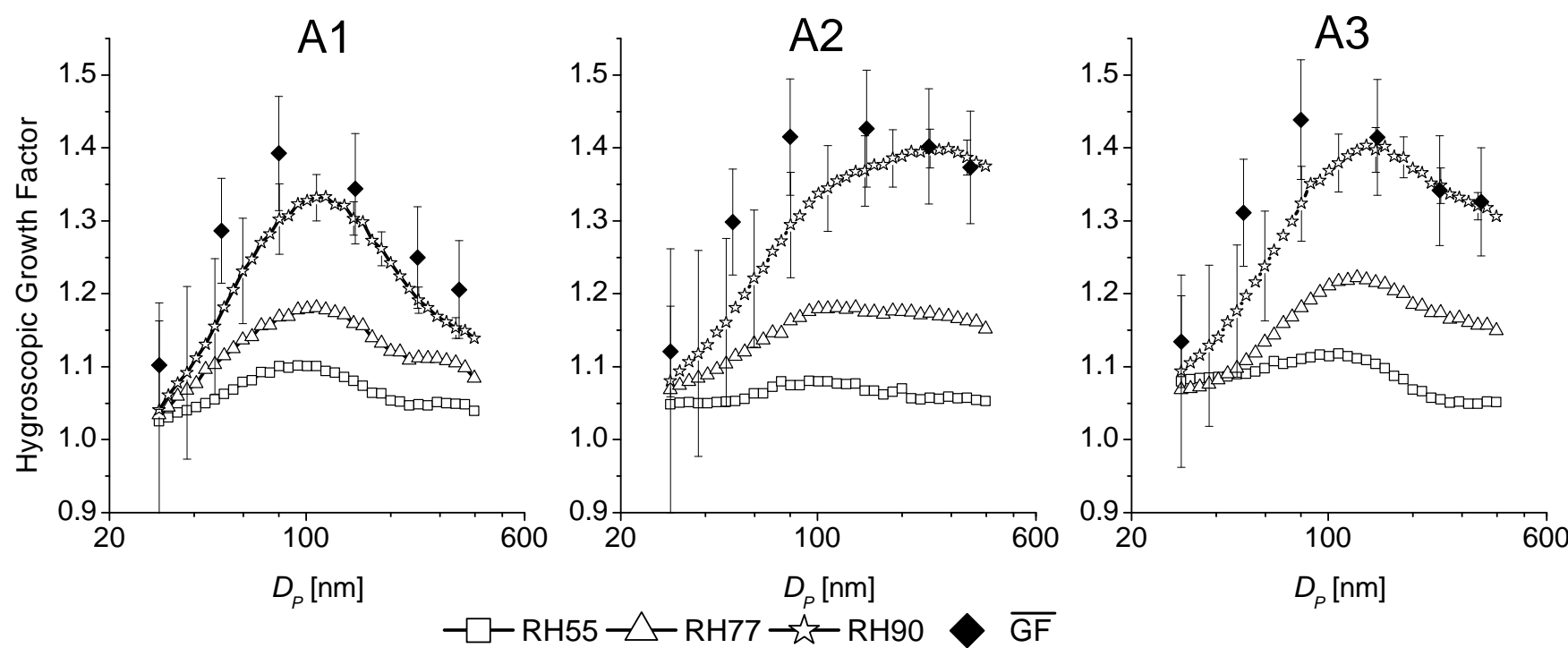

Fig. 5. Descriptive hygroscopic growth factors as a function of particle size for the three investigated air masses (A1, A2, A3). Data derived from the H-DMPS/TDMPS are shown for three selected relative humidities $(\mathrm{RH}=55 \%, 77 \%$ and $90 \%)$, complemented by individual data points obtained by the H-TDMA at six particle diameters $(30 \mathrm{~nm}, 50 \mathrm{~nm}, 80 \mathrm{~nm}, 150 \mathrm{~nm}, 250 \mathrm{~nm}, 350 \mathrm{~nm})$ and $90 \%$ relative humidity. Whiskers indicate the measurement uncertainties.

Table 3. Hygroscopic descriptive growth factors, calculated based on the number size distributions of TDMPS and H-DMPS measurements for three different time periods (A1, A2, A3) at a relative humidity of $\mathrm{RH}=55 \%, 77 \%$ and $90 \%$ and for the impactor sampling periods (I1, $\mathrm{I} 2, \mathrm{I} 3)$ at $90 \%$.

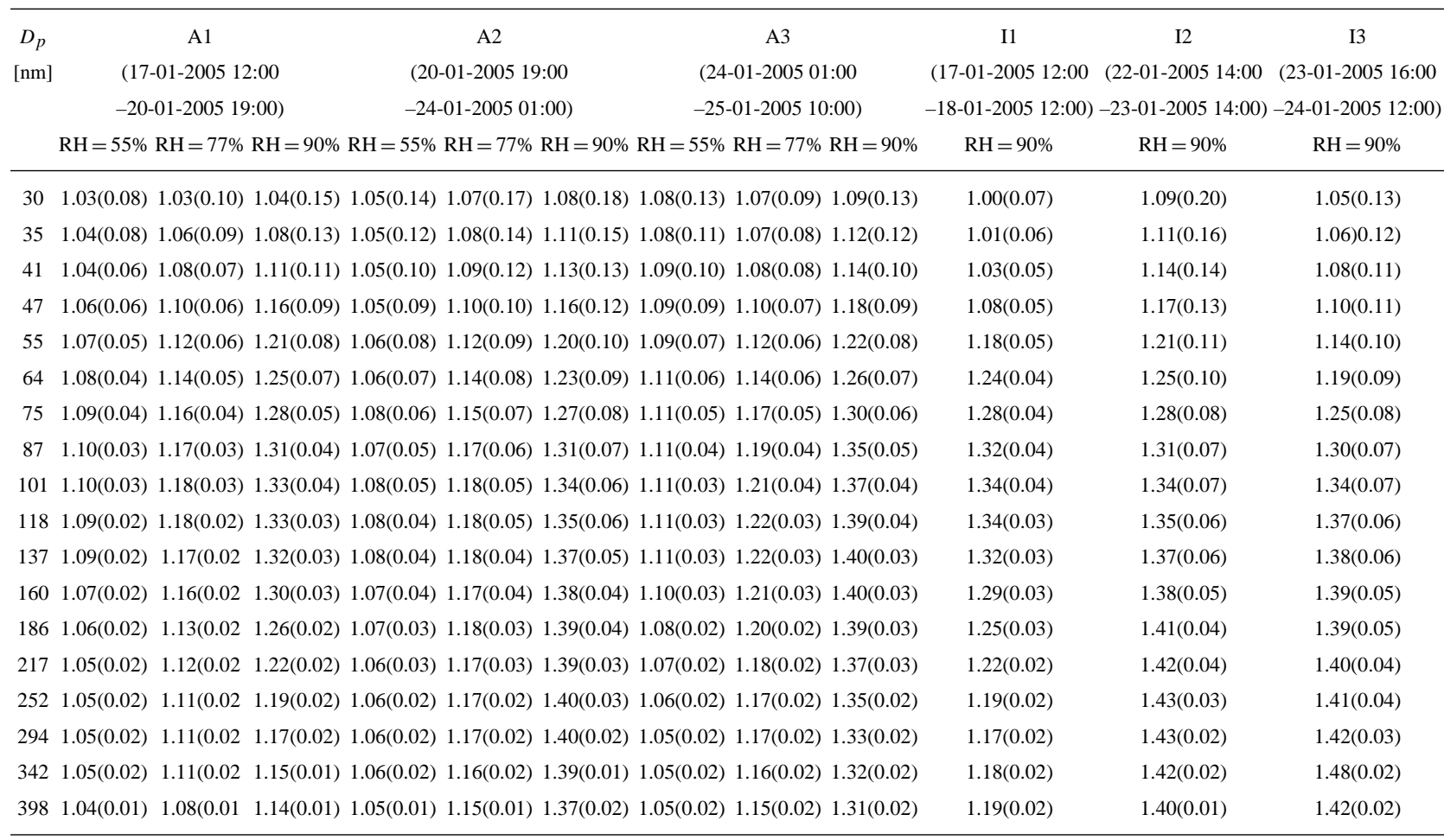



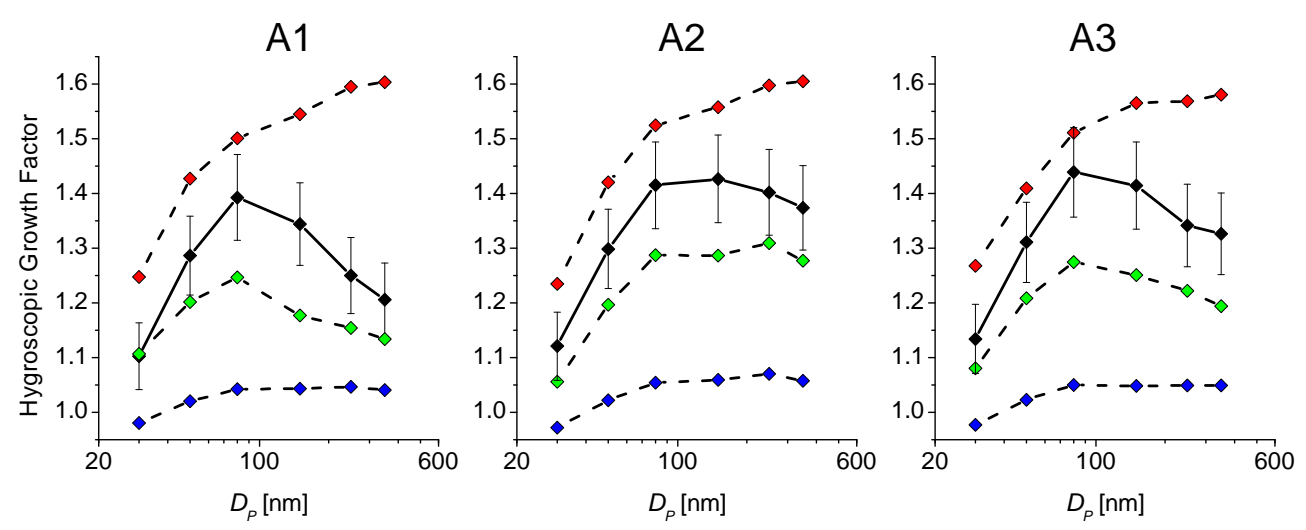

- more hygroscopic $-\diamond$-less hygroscopic $->$ - nearly hydrophobic -
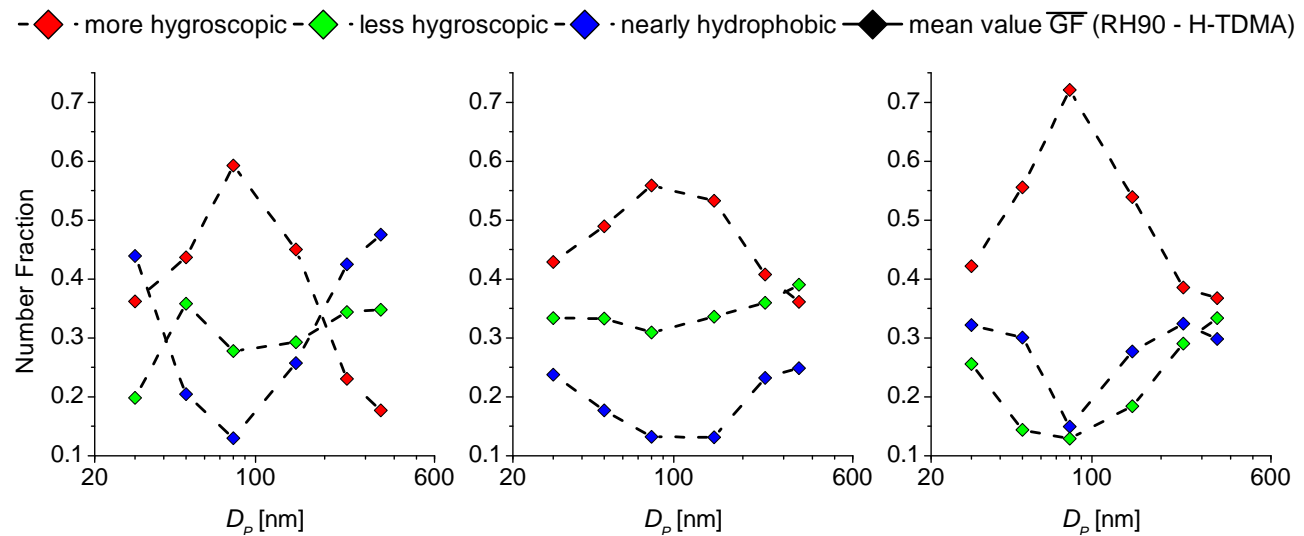

Fig. 6. Growth factors (upper row) and number fractions (lower row) of "nearly hydrophobic", "less hygroscopic" and "more hygroscopic" particles, measured by H-TDMA, for the three air masses (A1 (left column), A2 (middle column), A3 (right column)).

For air mass A2, the descriptive hygroscopic growth factors were higher compared to A1. The hygroscopic growth factors were similar for particle sizes greater than $80 \mathrm{~nm}$ at $\mathrm{RH}=55 \%$ and $77 \%$. The maximum growth factor of $1.40(0.03)$ was observed for the size range $200-300 \mathrm{~nm}$ at $\mathrm{RH}=90 \%$, which is interpreted as the result of the production of soluble secondary aerosol during transport over land. Air mass A2 was strongly influenced by regional and local anthropogenic sources, with sulphate being a distinguished compound determining particle hygroscopicity in these air masses (Achtert et al., 2009).

During air mass A3, the shape of the DHGF curves changed in comparison to A2. For all three relative humidities, the growth factors of particles larger than $200 \mathrm{~nm}$ were lower than in air mass A2. The maximum of the growth factors of $1.40(0.03)$ occurred at $150 \mathrm{~nm}$. Due to the meteorological conditions the data for air mass A3 can be considered a hybrid of the corresponding data for air masses A1 and A2. It is worth to note that for $D_{p}<40 \mathrm{~nm}$, the DHGF at $55 \% \mathrm{RH}$ exceeds that at $77 \% \mathrm{RH}$. Such behaviour is unrealistic, and represents an example for the enhanced measurement uncertainty of the evaluation method at the lower size distribution end (Sect. 3.1).

\subsubsection{H-TDMA growth factors and number fractions}

The hygroscopic growth of selected particle diameters (30, $50,80,150,250$ and $350 \mathrm{~nm}$ ) at $\mathrm{RH}=90 \%$ was examined using a H-TDMA. Figure 6 presents the growth factors (GF) and number fractions (nf) of three distinct particle classes, "nearly hydrophobic", "less hygroscopic" and "more hygroscopic" particles. Table 4 provides a complete summary of the observations. Additionally, the mean hygroscopic growth factor $\overline{\mathrm{GF}}$ (calculated after Eq. 2), is presented in the top of Fig. 6 for all three time periods (A1, A2, A3).

A first observation is that the nearly hydrophobic particles have a rather constant GF for particles $\geq 80 \mathrm{~nm}$, which is also independent of the air mass. At least the particles $\geq 80 \mathrm{~nm}$ are interpreted as the result of fresh emissions from combustion sources.

The GFs of the more hygroscopic particles are also rather invariant with air mass, and range between 1.23 at $30 \mathrm{~nm}$ and 1.61 at $350 \mathrm{~nm}$. The GF of the more hygroscopic particles increase monotonously with particle diameter, suggesting an increasing mass fraction of soluble material. However, the GF of the more hygroscopic type does still not reach the growth factor of a pure ammonium sulphate aerosol (1.74 at $350 \mathrm{~nm}$ ). In contrast to both modes described above, the 
Table 4. Number fractions (nf) and hygroscopic growth factors (GF) for "more hygroscopic" ( $\left.n f_{1}, G F_{1}\right)$, "less hygroscopic" $\left(n f_{2}, G F_{2}\right)$, and "nearly hydrophobic" $\left(n f_{3}, G F_{3}\right)$ particles, measured by H-TDMA at RH $=90 \%$ for the three different air masses (A1, A2, A3) and the impactor sampling periods (I1, I2, I3). According to equation 2 the calculated $\overline{\mathrm{GF}}$ for all periods is noted.

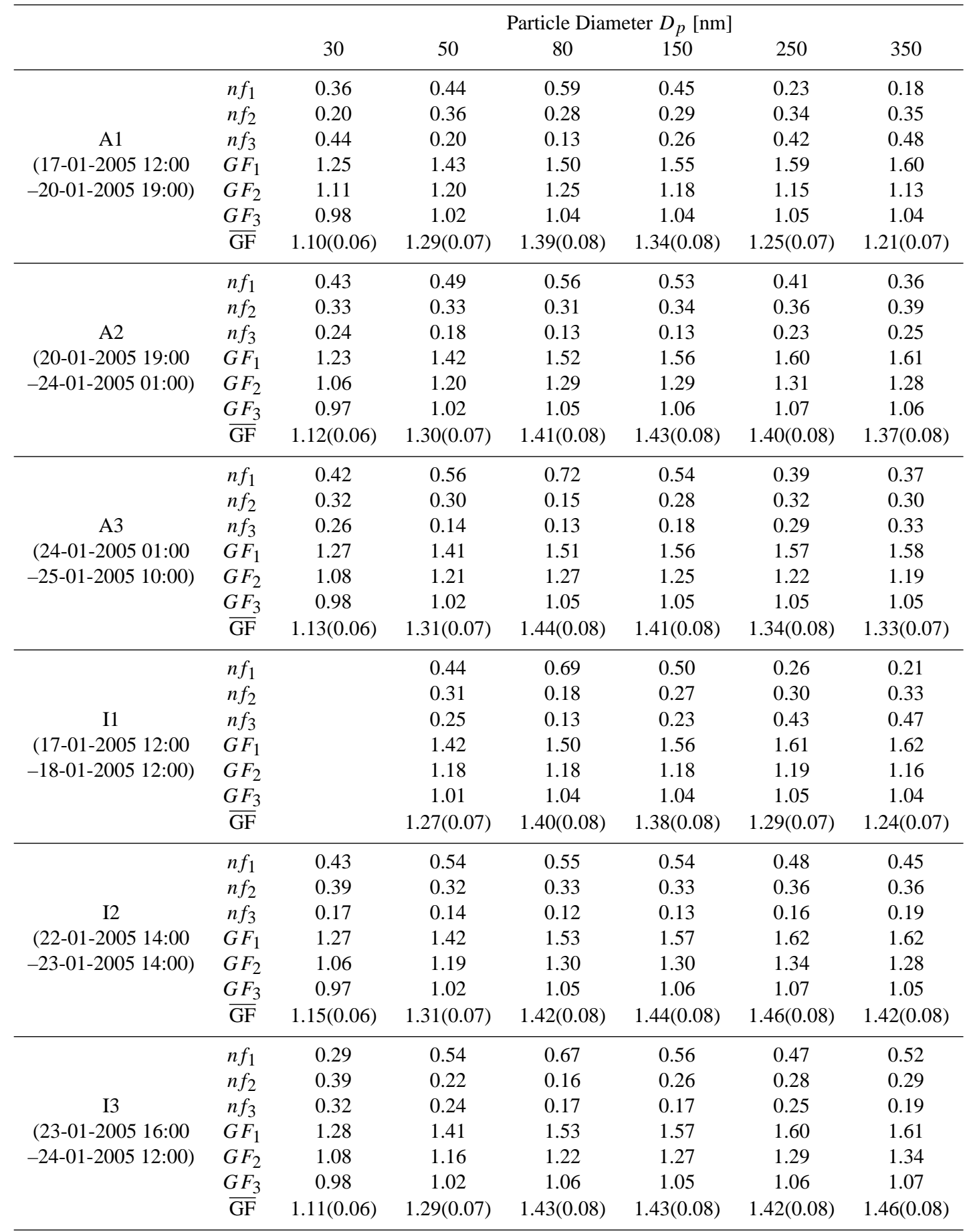

less hygroscopic particle type shows no plain dependency on particle diameter, and differs more significantly between the three air masses.
In contrast to GF, the number fractions of the three particle types are more variant with diameter, and also air mass type. The more hygroscopic particles attain their largest number fraction around $D_{p}=80 \mathrm{~nm}(0.56-0.72)$. Towards bigger 
and smaller particles, their number fraction decreases. The dependency of the number fraction of the nearly hydrophobic type mirrors the behaviour of the more hygroscopic type: A minimum is reached for $D_{p}=80 \mathrm{~nm}(0.13)$, increasing towards bigger and smaller particles. The less hygroscopic particle type shows, again, no plain behaviour.

From the above results it is evident that the sizedependency of the hygroscopicity of the total aerosol depends essentially on the mixing ratio between nearly hydrophobic and more hygroscopic particles. A notable feature, which is also highly relevant for the climate effects of the aerosol, is the increasing contribution of nearly hydrophobic at particle diameters $>100 \mathrm{~nm}$. This emphasises the relevance of primary emissions - likely to be soot from combustion sources, for the aerosol under study. Second, hygroscopic growth factors of the less and more hygroscopic particles observed within this study were slightly smaller in comparison to those found at several other urban sites (Swietlicki et al., 2008). This indicates that insoluble carbonaceous matter was a significant component in all particle groups of the sub- $\mu \mathrm{m}$ aerosol in Beijing during wintertime. This behaviour was eminently observed for particles with $D_{p}=150 \mathrm{~nm}$.

\subsubsection{H-DMPS/TDMPS vs. H-TDMA results}

The results for the H-DMPS/TDMPS and the H-TDMA are now compared quantitatively for $\mathrm{RH}=90 \%$. Figure 5 compares DHGF and $\overline{\mathrm{GF}}$ (from Fig. 6) for the air mass periods A1, A2 and A3 as a function of particle size. As can be seen from Figure 5, $\overline{\mathrm{GF}}$ is in qualitative agreement with DHGF. As an overall trend, the H-TDMA growth factors are slightly higher than the DHGFs but the dependency on particle size is very similar in both methods. For A1, we see a rather constant shift, with a mean difference of 0.07 between $\overline{\mathrm{GF}}$ and DHGF. For the larger particles $\left(D_{p} \geq 150 \mathrm{~nm}\right)$, the differences in growth factor are slightly smaller (0.05). For the high polluted period A2, the mean discrepancy between the two methods is around 0.06 but remarkably better ( 0 and 0.03 ) for $D_{p}=250-350 \mathrm{~nm}$. The best agreement between $\overline{\mathrm{GF}}$ and DHGF was found for air mass A3. Here, the mean difference was 0.05 , and only 0.01 for particles $D_{p} \geq 250 \mathrm{~nm}$.

The direct correlation between both methods is visualised in Fig. 7. It can be seen that the slope of the linear fit curve is close to 1 for the particle diameters 250 and $350 \mathrm{~nm}$, and still 0.87 for $150 \mathrm{~nm}$. However, it drops to 0.4 in the case of $50 \mathrm{~nm}$. In view of the narrower deviations within the $\overline{\mathrm{GF}}$ data compared to the DHGFs, and the lower complexity of the H-TDMA evaluation, one might consider the H-TDMA as the better defined method. Our data set collected here is, however, not sufficient to substantiate the underlying reasons for the divergences at smaller particle diameters. Additional calibration and test measurements will be needed in the future to understand the limitations of the H-DMPS/TDMPS method.
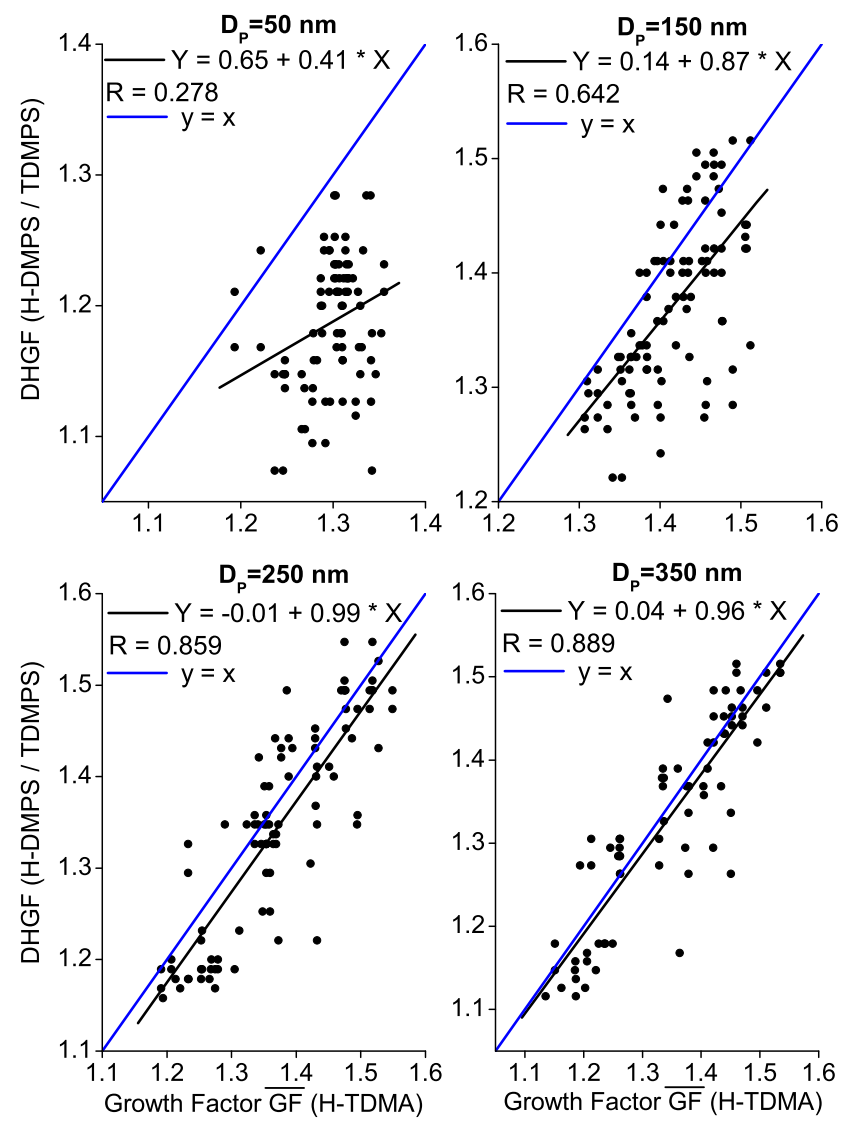

Fig. 7. Correlation coefficients for $D_{p}=50 \mathrm{~nm}$ (top left), $D_{p}=150 \mathrm{~nm} \quad$ (top right), $D_{p}=250 \mathrm{~nm} \quad$ (down left) and $D_{p}=350 \mathrm{~nm}$ (down right) between the DHGF (H-DMPS/TDMPS) and the $\overline{\mathrm{GF}}$ (H-TDMA).

\subsection{CHGFs from chemical composition}

The CHGFs calculated for $\mathrm{RH}=90 \%$ in Sect. 3.3 are summarised in Table 5. Calculations were made for the three sampling periods I1, I2 and I3. For the comparison, DHGF and $\overline{\mathrm{GF}}$ results were averaged over the same periods. For period $\mathrm{I} 2$ and $\mathrm{I} 3$, an average of 13 and 9 DHGF valid data points could be averaged, respectively. Unfortunately, for period I1, only a single DHGF was available to compare with the model results. In the case of H-TDMA measurements (cf. Table 4), the data capture was limited as well. During I1, no, one, and two measurement points were available for the diameters $30 \mathrm{~nm}, 50-80 \mathrm{~nm}$, and $\geq 150 \mathrm{~nm}$, respectively. For period I2, between 9 and 12 measurement points were available for each size channel. During the third period (I3), between 4 and 8 measurement points were available.

Figure 8 displays the comparison of CHGF, DHGF, and $\overline{\mathrm{GF}}$. For clarity, only the results on the runs 1,3 and 6 (cf. Table 1) are presented. (The results of the other runs were found to reside between the other three.) As can be seen 
Table 5. Hygroscopic descriptive growth factors, calculated by a model based on the particles collected with MOUDI (I1, I2, I3) at a relative humidity of $\mathrm{RH}=90 \%$.

\begin{tabular}{cccccccc}
\hline Time Period & $\begin{array}{c}D_{p} \\
{[\mathrm{~nm}]}\end{array}$ & Run 1 & Run 2 & Run 3 & Run 4 & Run 5 & Run 6 \\
& 76 & $1.28(0.14)$ & $1.38(0.18)$ & $1.28(0.14)$ & $1.28(0.14)$ & $1.38(0.18)$ & $1.38(0.18)$ \\
I1 & 136 & $1.32(0.16)$ & $1.41(0.19)$ & $1.32(0.16)$ & $1.32(0.16)$ & $1.41(0.19)$ & $1.41(0.19)$ \\
$(17-01-200512: 00$ & 243 & $1.31(0.15)$ & $1.31(0.15)$ & $1.30(0.14)$ & $1.26(0.13)$ & $1.31(0.15)$ & $1.38(0.17)$ \\
$-18-01-200512: 00)$ & 425 & $1.29(0.13)$ & $1.19(0.09)$ & $1.17(0.08)$ & $1.14(0.07)$ & $1.30(0.13)$ & $1.35(0.15)$ \\
& 762 & $1.19(0.08)$ & $1.11(0.05)$ & $1.09(0.04)$ & $1.05(0.03)$ & $1.21(0.09)$ & $1.26(0.11)$ \\
\hline & 75 & $1.28(0.13)$ & $1.35(0.16)$ & $1.28(0.13)$ & $1.28(0.13)$ & $1.35(0.16)$ & $1.35(0.16)$ \\
I2 & 135 & $1.32(0.15)$ & $1.40(0.18)$ & $1.32(0.15)$ & $1.32(0.15)$ & $1.40(0.18)$ & $1.40(0.18)$ \\
$(22-01-200514: 00$ & 240 & $1.34(0.16)$ & $1.39(0.18)$ & $1.34(0.16)$ & $1.34(0.16)$ & $1.39(0.18)$ & $1.39(0.18)$ \\
$-23-01-200514: 00)$ & 421 & $1.30(0.14)$ & $1.35(0.16)$ & $1.30(0.14)$ & $1.30(0.14)$ & $1.35(0.16)$ & $1.35(0.16)$ \\
& 757 & $1.22(0.10)$ & $1.22(0.10)$ & $1.21(0.10)$ & $1.19(0.09)$ & $1.22(0.10)$ & $1.26(0.12)$ \\
\hline I3 & 75 & $1.36(0.17)$ & $1.42(0.19)$ & $1.36(0.17)$ & $1.36(0.17)$ & $1.42(0.19)$ & $1.42(0.19)$ \\
& 135 & $1.35(0.17)$ & $1.42(0.19)$ & $1.35(0.17)$ & $1.35(0.17)$ & $1.42(0.19)$ & $1.42(0.19)$ \\
$(23-01-200516: 00$ & 240 & $1.39(0.18)$ & $1.43(0.19)$ & $1.39(0.18)$ & $1.39(0.18)$ & $1.43(0.19)$ & $1.43(0.19)$ \\
$-24-01-200512: 00)$ & 421 & $1.38(0.18)$ & $1.41(0.19)$ & $1.38(0.18)$ & $1.38(0.18)$ & $1.41(0.19)$ & $1.41(0.19)$ \\
& 758 & $1.29(0.13)$ & $1.24(0.11)$ & $1.24(0.11)$ & $1.22(0.11)$ & $1.24(0.11)$ & $1.33(0.15)$ \\
\hline
\end{tabular}
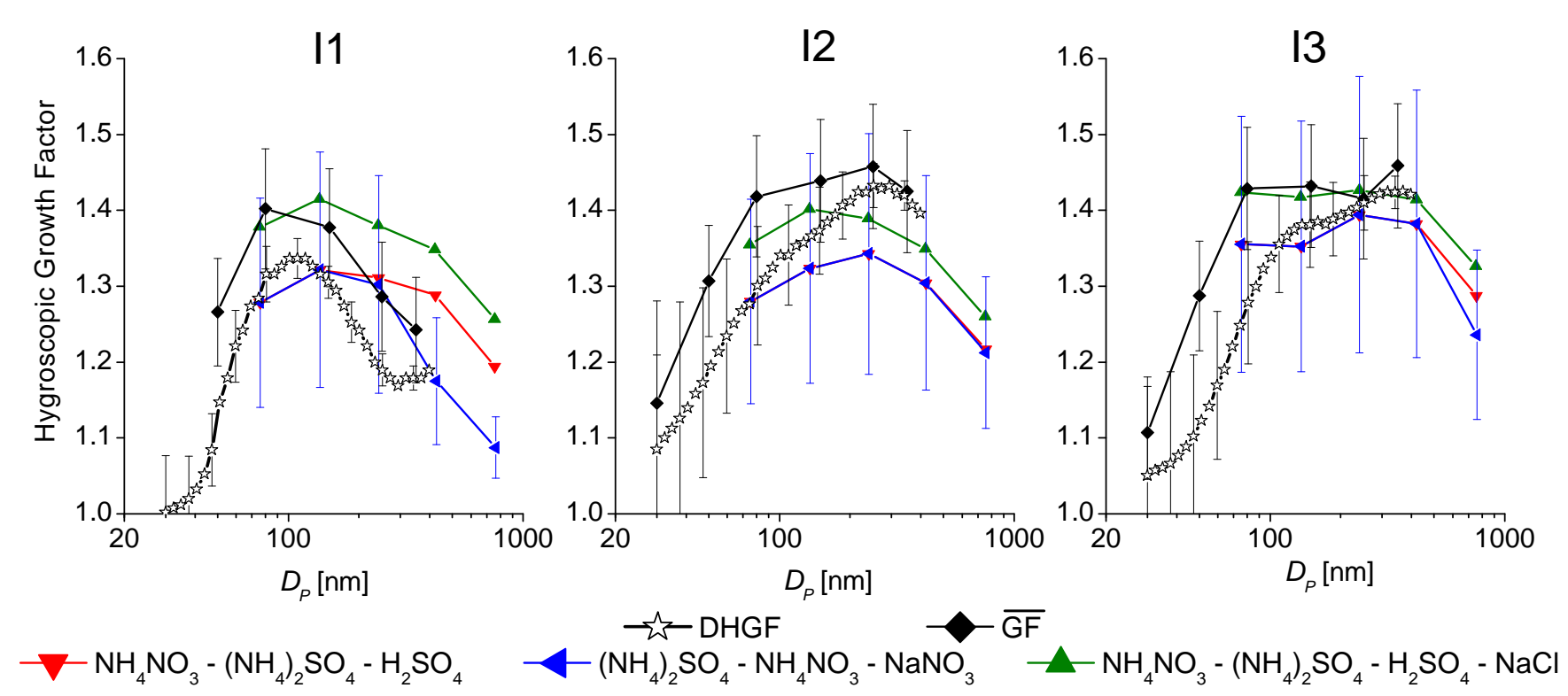

Fig. 8. Descriptive hygroscopic growth factor (DHGF) distributions based on TDMPS and H-DMPS measurements, mean growth factors $\overline{\text { GF }}$ at 6 particle diameters $(30 \mathrm{~nm}, 50 \mathrm{~nm}, 80 \mathrm{~nm}, 150 \mathrm{~nm}, 250 \mathrm{~nm}$ and $350 \mathrm{~nm})$ based on H-TDMA measurements and three runs of the chemical composition-based hygroscopic growth factors (CHGFs) determined at $\mathrm{RH}=90 \%$ based on MOUDI samples during the three measurement periods (I1, I2, I3).

in the Figure, CHGF and DHGF agreed only partly. Importantly, the size-segregated trend in particle hygroscopicity - high growth factors around $100 \mathrm{~nm}$, with a decreasing trend towards smaller and bigger particles, was detected by all methods.

In case of impactor sampling period I1 (Fig. 8, I1), the results of the model correspond with the DHGF although there is just one measurement to compare with, which might however not be representative. Nevertheless, there is a wide range between the model results, especially for the larger particle sizes. The discrepancies between the DHGFs and the CHGFs for the entire diameter range are 0.06 (Run 1), 0.08 (Run 2), 0.03 (Run 3, Run 4), 0.10 (Run 5) and 0.13 (Run 6 ) and therefore strongly dependent on the chosen chemical 
composition. For particles larger than $100 \mathrm{~nm}$ the discrepancies vary between 0.04 and 0.15 . During the first sampling period, the concentrations of $\mathrm{NO}_{3}^{-}$and $\mathrm{NH}_{4}^{-}$for smaller particle diameters were low compared to the other two periods leading in principle to larger uncertainties.

The model runs for impactor sampling period I2 (Fig. 8, I2) do show differences between the different model runs and the measurements. The maximum of the DHGF distribution is not well represented by the model. For particles larger than $100 \mathrm{~nm}$, the runs underestimate the DHGF. However, the general tendency of increasing growth for smaller and decreasing growth for larger particles is reflected by all model calculations. The particle mass concentration was largest during this period (Table 2), but the fraction of the unknown material was also very large, which increased the uncertainty in this case. For the unknown particle fraction, we used a growth factor of one leading to a decreased mean CHGF, which could be a reason for the underestimation. The discrepancies between the DHGF and the CHGF are 0.05-0.06 (60-800 nm particles) and 0.04-0.07 ( $\left.D_{p} \geq 100 \mathrm{~nm}\right)$, respectively, less than during I1.

The comparison between the model runs (Fig. 8, I3) and the measurements is best for the last impactor sampling period I3. There are no significant differences between the model results (CHGFs) and the measured DHGFs for particles with diameters larger than $100 \mathrm{~nm}$. The mean discrepancies vary between 0.05 and 0.06 (70-400 nm particles). The agreement for particles larger than $100 \mathrm{~nm}$ is still better with $0.02-0.03$. The chemical composition of the third impactor sampling period was mainly determined by the strong pollution during observation of air mass A2 indicating that the chemical composition was more homogeneous and the model results were probably better comparable with the measured hygroscopic growth factors.

According to the hygroscopic growth factors determined from the H-TDMA $(\overline{\mathrm{GF}})$, the agreement with DHGF is nearly as good like for the comparison for A1, A2 and A3. But here, the better agreement with increasing particle diameters is not so strong for I1, I2 and I3, like during A1, A2 and A3. Whereas during $\mathrm{I} 2$ the H-TDMA data are larger than the DHGF and the CHGF, the agreement for I1 between $\overline{\mathrm{GF}}$ and CHGF is satisfying. Here, for lower particle diameters $\left(D_{p} \leq 150 \mathrm{~nm}\right)$ results of Run 6 and for larger particle diameters $\left(D_{p} \geq 250 \mathrm{~nm}\right)$ results of Run 3 do better correspond with $\overline{\mathrm{GF}}$. CHGFs calculated by Run 6 are very consistent with the hygroscopic growth factors determined by the H-TDMA. $\overline{\text { GF }}$ support the hygroscopic growth factors, calculated by the simple solubility model, although a perfect agreement was not reached.

Although clear differences are visible between the growth factors derived by the three methods, the size-segregated trend in particle hygroscopicity - apparently a result of sizedependent particle composition, is recognised by all methods. The absolute differences between the methods are, how- ever, not surprising facing the uncertainties and shortcomings related to each method. A limitation of the current H-DMPS/TDMPS method seems to be the inaccurate apportionment of dry and humidified particles in the lower size range ( $<70 \mathrm{~nm}$; cf. also Birmili et al., 2009). Essential limitation of the composition-based calculations are the need to subtract particle-bound water from the samples collected at $52 \% \mathrm{RH}$, the uncertain particle density, but also the poorly characterised hygroscopic growth of the organic and "unspecified" chemical fractions. While the H-TDMA method appears rather well-defined to characterise individual hygroscopic fractions, uncertainties are induced when calculating $\overline{\mathrm{GF}}$ from the parameters related to these individual fractions.

\section{Conclusions}

The hygroscopicity of ambient particles in the urban atmosphere of Beijing was characterised using multiple methods. The methods included the concurrent measurement of humidified and dry particle number size distributions (H-DMPS/TDMPS), a Hygroscopic Tandem DMA (HTDMA), and calculations based on measured chemical particle composition.

The measurement campaign was divided into three subperiods corresponding to different degrees of total particle mass concentration. Relatively clean air with a mass concentration of $44 \mu \mathrm{g} \mathrm{m}^{-3}$ could be contrasted with polluted air with a mass concentration of $207 \mu \mathrm{g} \mathrm{m}^{-3}$. The classes of chemical particulate species involved in the accumulation mode aerosol were, in order of relevance, organic matter $(\mathrm{OM})$, ammonium sulphate, and elemental carbon.

From the H-DMPS and TDMPS size distributions, descriptive hygroscopic growth factors (DHGFs) were derived using the summation method. The lowest DHGFs (at $90 \%$ $\mathrm{RH})$ in the accumulation mode $\left(D_{p}=120 \mathrm{~nm}\right)$ were observed in clean continental air $(1.33 \pm 0.03)$. In polluted air advected to Beijing from southerly directions, DHGF increased to $1.40( \pm 0.03)$ for $200-300 \mathrm{~nm}$ particles. These DHGFs were significantly lower than corresponding observations in the rural aerosol south of Beijing in summer 2006 ( 1.6; Achtert et al., 2009).

H-TDMA measurements revealed an external mixture of three different hygroscopic particle modes ("nearly hydrophobic", "less hygroscopic", and "more hygroscopic"), which had also been identified in previous atmospheric studies (Swietlicki et al., 2008). The H-TDMA confirm a trend towards bigger growth factors along with particle size (30$350 \mathrm{~nm}$ ) for the more hygroscopic mode, consistent with an increasing relevance of soluble material in bigger particles. Interestingly, however, the average particle growth factor $\overline{\mathrm{GF}}$ was found to decrease above $100 \mathrm{~nm}$ due to an increasing fraction of hydrophobic particles. This is indicative of a significant fraction of freshly emitted particles from combustion in the accumulation mode. 
When compared for concurrent periods, the DHGF values were lower by $0.0-0.12(90 \% \mathrm{RH})$ compared to $\overline{\mathrm{GF}}$. The agreement between the two methods was best for bigger particles (250 and $350 \mathrm{~nm}$ ), and became worse when passing over to the lowest diameter $50 \mathrm{~nm}$. We interpret this as a limitation of the summation method, where segments of the particle number size distributions are associated with each other. In line with a previous analysis of H-DMPS/TDMPS data (Birmili et al., 2009) we assume that the DHGF values are accurate only in the range $D_{p}>70 \mathrm{~nm}$.

As a third method, chemical composition-based hygroscopic growth factors (CHGFs) were calculated for $90 \% \mathrm{RH}$ on the basis of MOUDI impactor samples spanning three sampling periods. An impactor sample encompassed six size fractions in the sub- $\mu \mathrm{m}$ range. It was noted that the solubility model provided different CHGFs depending on how the positive and negative ions were apportioned. In the relatively clean continental air the CHGFs exceeded the growth factors determined by the other methods within a discrepancy of $0.03-0.13$. In polluted air, the discrepancy was lower $(0.05-$ 0.06 ). Nearly perfect agreement was for the last sample (I3), with a mean deviation of $0.02-0.03$ for $100-400 \mathrm{~nm}$ particles. Taking into account the uncertainty of each method, the observed divergences in the absolute growth factor values are not surprising. However, even if the absolute growth factor values were not matched, it could be seen that all three methods recognised the clear size dependency of the hygroscopic growth factor, which is a consequence of size-dependent chemical composition. All methods suggested a maximum hygroscopic growth factor in the accumulation mode range (100-300 nm).

Our work demonstrates the capability as well as the limitations of different methods using physical instruments (H-DMPS/TDMPS, H-TDMA), or chemical analysis of impactor samples combined with a solubility model to qualitatively determine the hygroscopic growth of environmental particles as a function of particle size. In the future, improvements would be desirable with respect to the accuracy of the H-DMPS/TDMPS, but also the more detailed characterisation of organic and "unspecified" chemical compounds and their hygroscopic behaviour.

The data collected in the city of Beijing in wintertime showed lower growth factors than in the same area in summertime, likely the result of the high carbonaceous fraction in the observed aerosol. The results are relevant for the prediction of aerosol radiative effects as well as visibility impacts in this socio-economically rapidly changing region.

Acknowledgements. This work was supported by DFG (Deutsche Forschungsgemeinschaft) grant WI 1449/9-1/2. The data evaluation was supported by the European Integrated project on Aerosol Cloud Climate and Air Quality Interactions (EUCAARI), coordinated by the University of Helsinki, Finland.

Edited by: V.-M. Kerminen

\section{References}

Achtert, P., Birmili, W., Nowak, A., Wehner, B., Wiedensohler, A., et al.: Hygroscopic growth of tropospheric particle number size distributions over the North China Plain, J. Geophys. Res., 114, D00G07, doi:2008JD010921, 2009.

Bergin, M. H., Cass, G. R., Xu, J., Fang, C., Zeng, L. M., et al.: Aerosol radiative, physical, and chemical properties in Beijing during June 1999, J. Geophys. Res., 106(D16), 17969-17980, 2001.

Birmili, W., Stratmann, F., and Wiedensohler, A: Design of a DMAbased size spectrometer for a large particle size range and stable operation, J. Aerosol Sci., 30, 4, 549-553, 1999.

Birmili, W., Schwirn, K., Nowak, A., Petäjä, T., Joutsensaari, J., et al.: Measurements of humidified particle number size distributions in a Finnish boreal forest: derivation of hygroscopic particle growth factors, Boreal Environ. Res., 14, 458-480, 2009.

Brüggemann, E. and Rolle, W.: Changes of some components of precipitation in East Germany after the unification, Water Air Soil Pollut., 107, 1-23, 1998.

Cao, J. J., Lee, S. C., Ho, K. F., Zhang, X. Y., Zou, S. C., et al.: Characteristics of carbonaceous aerosol in Pearl River Delta Region, China during 2001 winter period, Atmos. Environ., 37, 1451-1460, 2003.

Charlson, R. J. and Heintzenberg, J.: Aerosol forcing of climate, John Wiley and Sons Ltd., Chichester, 416 pp., 1995.

Cheng, Y. F., Wiedensohler, A., Eichler, H., Heintzenberg, J., Tesche, M., et al.: Relative humidity dependence of aerosol optical properties and direct radiative forcing in the surface boundary layer at Xinken in Pearl River Delta of China: An observation based numerical study, Atmos. Environ., 42, 6373-6397, 2008.

Cocker, D., Whitlock, N., Flagan, R., and Seinfeld, J. H.: Hygroscopic properties of Pasadena, California aerosol, Aerosol Sci. Technol, 35, 2, 637-647, 2001.

Draxler, R. R. and Hess, G. D.: Description of the HYSPLIT-4 modeling system, NOAA Technical Memorandum ERL ARL-224, $25,2004$.

Eichler, H., Cheng, Y. F., Birmili, W., Nowak, A., Wiedensohler, A., et al.: Hygroscopic properties and extinction of aerosol particles at ambient relative humidity in South-Eastern China, Atmos. Environ., 42, 6321-6334, 2008.

Fenger, J.: Urban air quality, Atmos. Environ., 33, 4877-4900, 1999.

Ferron, G., Karg, E., Busch, B., and Heyder, J.: Ambient particles at an urban, semi-urban and rural site in Central Europe: Hygroscopic properties, Atmos. Environ., 39, 343-352, 2005.

Florig, H. K.: China's air pollution risks, Environ. Sci. Technol., 31, 6, 274A-279A, 1997.

Gysel, M., Weingartner, E., Nyeki, S., Paulsen, D., Baltensperger, U., et al.: Hygroscopic properties of water-soluble matter and humic-like organics in atmospheric fine aerosol, Atmos. Chem. Phys., 4, 35-50, 2004,

http://www.atmos-chem-phys.net/4/35/2004/.

Jinhuan, Q. and Liquan, Y.: Variation characteristics of atmospheric aerosol optical depths and visibility in North China during 19801994, Atmos. Environ., 34, 603-609, 2000.

Mage, D., Ozolins, G., Peterson, P., Webster, A., Orthofer, R., et al.: Urban air pollution in megacities of the world, Atmos. Environ., 30, 681-686, 1996.

Marple, V. A., Rubow, K. L., and Behm, S. M.: A Microorifice 
Uniform Deposit Impactor (MOUDI): Description, calibration, and use, Aerosol Sci. Technol., 14, 434-446, 1991.

Massling, A., Stock, M., Wehner, B., Wu, Z. J., Hu, M., et al.: Size segregated water uptake of the urban submicrometer aerosol in Beijing, Atmos. Environ., 43, 1578-1589, 2009.

Massling, A., Stock, M., and Wiedensohler, A.: Diurnal, weekly, and seasonal variation of hygroscopic properties of submicrometer urban aerosol particles, Atmos. Environ., 39, 3911-3922, 2005.

Massling, A., Wiedensohler, A., Busch, B., Neusüss, C., Quinn, P., et al.: Hygroscopic properties of different aerosol types over the Atlantic and Indian Oceans, Atmos. Chem. Phys., 3, 1377-1397, 2003 , http://www.atmos-chem-phys.net/3/1377/2003/.

McMurry, P. and Stolzenburg, M.: On the sensitivity of particle size to relative humidity for Los Angeles aerosols, Atmos. Environ., 23, 497-507, 1989.

Neusüss, C., Pelzing, M., Plewka, A., and Herrmann, H.: A new analytical approach for size-resolved speciation of organic compounds in atmospheric aerosol particles: Methods and first results, J. Geophys. Res., 105, D4, 4513-4527, 2000.

Pitz, M., Schmid, O., Heinrich, J., Birmili, W., Maguhn, J., et al.: Seasonal and diurnal variation of PM 2.5 apparent particle density in urban air in Augsburg, Germany, Env. Sci. Technol., 42, 14, 5087-5093, 2008.

Rader, D. J. and McMurry, P. H.: Application of the Tandem Differential Mobility Analyzer to studies of droplet growth or evaporation, J. Aerosol Sci., 17, 5, 771-787, 1986.

Stokes, R. H. and Robinson, R. A.: Interactions in Aqueous Nonelectrolyte Solutions. I. Solute-Solvent Equilibria, J. Phys. Chem., 70, 2126-2130, 1966.

Sugimoto, N., Uno, I., Nishikawa, M., Shimizu, A., Matsui, I., et al.: Record heavy Asian dust in Beijing in 2002: Observations and model analysis of recent events, Geophys. Res. Lett. 30(12), 1640, doi:2002GL016349, 2003.

Swietlicki, E., Hansson, H.-C., Hämeri, K., Svenningsson, B., Massling, A., et al.: Hygroscopic properties of submicrometer atmospheric aerosol particles measured with H-TDMA instruments in various environments - a review, Tellus B, 60(3), 432469, 2008.

Tang, A., Zhuang, G., Wang, Y., Yuan, H., and Sun, Y: The chemistry of precipitation and its relation to aerosol in Beijing, Atmos. Environ., 39, 3397-3406, 2005.

Tang, I. N. and Munkelwitz, H. R.: Water activities, densities, and refractive indices of aqueous sulfates and sodium nitrate droplets of atmospheric importance, J. Geophys. Res., 99(D9), 1880118808, 1994.
Tang, I., Wong, W., and Munkelwitz, H. R.: The relative importance of atmospheric sulfates and nitrates in visibility reduction, Atmos. Environ., 15, 2463-2471, 1981.

Turpin, B. J. and Lim, H.-J.: Species contributions to $\mathrm{PM}_{2.5}$ mass concentrations: Revisiting common assumptions for estimating organic mass, Aerosol Sci. Technol., 35, 602-610, 2001.

VDI 2465 Part 2: Measurement of soot (ambient air), thermographic determination of elemental carbon after thermal desorption of organic carbon, VDI/DIN-Handbuch Reinhaltung der Luft, Band 4, 18, 1999.

Viidanoja, J., Sillanpää, M., Laakia, J., Kerminen, V.-M., Hillamo, R., et al.: Organic and black carbon in $\mathrm{PM}_{2.5}$ and $\mathrm{PM}_{10}$ : 1 year of data from an urban site in Helsinki, Finland, Atmos. Environ., 36, 3183-3193, 2002.

Wehner, B., Birmili, W., Ditas, F., Wu, Z., Hu, M., et al.: Relationships between submicrometer particulate air pollution and air mass history in Beijing, China, 2004-2006, Atmos. Chem. Phys., 8(20), 6155-6168, 2008.

Wehner, B., Wiedensohler, A., Tuch, T., Wu, Z. J., Hu, M., et al.: Variability of the aerosol number size distribution in Beijing, China: New particle formation, dust storms, and high continental background, Geophys. Res. Lett., 31, L22108, doi:2004GL021596, 2004.

Weingartner, E., Burtscher, H., and Baltensperger, U.: Hygroscopic properties of carbon and diesel soot particles, Atmos. Environ., 31, 2311-2327, 1997.

Wu, Z., Hu, M., Lin, P., Liu, S., Wehner, B., and Wiedensohler, A.: Particle number size distribution in the urban atmosphere of Beijing, China, Atmos. Environ., 42, 7967-7980, 2008.

Wu, Z., Hu, M., Liu, S., Wehner, B., Bauer, S., et al.: New particle formation in Beijing, China: Statistical analysis of a one-yeardataset, J. Geophys. Res., 112, D09209, doi:2006JD007406, 2007.

Xu, X., Gao, J., Dockery, D. W., Chen, Y.: Air pollution and daily mortality in residential areas of Beijing, China, Arch. Environ. Health, 49, 4, 216-222, 1994.

Yue, D., Hu, M., Wu, Z., Wang, Z., Guo, S., et al.: Characteristics of aerosol size distributions and new particle formation in the summer in Beijing, J. Geophys. Res., 114, D00G12, doi:2008JD010894, 2009.

Zdanovskii, A. B.: New methods of calculating solubilities of electrolytes in multicomponent systems, Zhur. Fiz. Kim., 22, 14751485, 1948.

Zhang, R., Wang, M., Zhang, X. and Zhu, G.: Analysis on the chemical and physical properties of particles in a dust storm in spring in Beijing, Powder Technol., 137(1-2), 77-82, 2003. 